\title{
Unusual Presenting Syndrome of Rheumatoid Arthritis Exacerbation
}

\author{
Tatiana Reitblat ${ }^{1}$, Olga Reitblat ${ }^{2}$, Ori Elkayam ${ }^{2}$ \\ ${ }^{1}$ Rheumatology Unit, Barzilai Medical Centre, Ashkelon, Israel; ${ }^{2}$ Department of Rheumatology, Tel Aviv Medical Centre and The \\ "Sackler" Faculty of Medicine, Tel Aviv University, Tel Aviv, Israel. \\ Email: reitblat@barzi.health.gov.il
}

Received November $4^{\text {th }}, 2011$; revised December $18^{\text {th }}, 2011$; accepted January $28^{\text {th }}, 2011$

\begin{abstract}
We herewith report the rare case of a patient with juvenile rheumatoid arthritis who developed on 2 occasions the clinical picture of an isolated unilateral palsy of the inferior oblique muscle-Brown's syndrome, following pregnancies, each time in a different eye. Although the eye is frequently involved in rheumatoid arthritis (RA), the Brown's syndrome is seldom reported in literature with regards to RA.
\end{abstract}

Keywords: Brown’s Syndrome; Juvenile Rheumatoid Arthritis; Rheumatoid Arthritis

\section{Introduction}

The eye is frequently involved in rheumatoid arthritis (RA). The most common manifestations are keratoconjunctivitis sicca, often resulting in corneal involvement, scleritis and episcleritis. However, other less frequent ocular features have been described [1]. We herewith report the case of a patient with juvenile rheumatoid arthritis who developed on 2 occasions the clinical picture of an isolated unilateral palsy of the inferior oblique muscle. Following pregnancies, each time in a different eye.

\section{Case Report}

A 40 years old woman, with a 25 year history of juvenile rheumatoid arthritis (JRA), developed sudden right eye gaze palsy together with arthritis exacerbation the first week after giving birth to her second child. She reported a normal $1^{\text {st }}$ pregnancy without after delivery complications. At this time, a few days after completing her second pregnancy, she presented with complains of diplopia at an upward-in gaze. During the pregnancy, the patient entered into remission of JRA, without need for medications. On physical examination, at presentation, she demonstrated severe synovitis of wrists, 2, 3, MCPs, 2 4 PIPs and knees. The ophthalmologic examination was consistent with right inferior oblique palsy. Laboratory tests revealed a normocytic-normochromic anemia, and raised ESR and CRP. Single bundle EMG of the ocular nerves excluded neurological pathology and muscle myopathy.
The patient was diagnosed as suffering from Brown syndrome. She was treated with Prednisolone $30 \mathrm{mg}$ a day and Methotrexate (MTX) 15 mg a week. Her diplopia slowly improved during the course of several weeks, resulting in a slight permanent disturbance of eye movement

A few years later, she had an uneventful $3^{\text {rd }}$ pregnancy but after her fourth delivery, she presented with a clinical picture similar to the one observed after her second pregnancy: arthritis exacerbation and diplopia. This time, the event involved the left eye, at an upward-in gaze. The patient was examined by an ophthalmologist, and diagnosed again as Brown syndrome. Treatment with MTX $15 \mathrm{mg}$ a week was renewed and Prednisolone dose raised to $30 \mathrm{mg}$ a day (the patient was treated by prednisolone 5 mg once a day during her fourth pregnancy). Her eye symptoms improved, although a mild residual diplopia remained.

The patient was treated by Prednisone $30 \mathrm{mg} / \mathrm{d}$ till the begining of improvement in her diplopia with slow Prednisone tapering after that in both cases.

\section{Discussion}

In 1973, Brown reported an unusual motility disorder, characterized by a limitation of upgaze in an adducted eye [2]. The cause of this malfunction is an abnormality of the superior oblique tendon, its sheath or the trochlea, preventing free passage of the tendon through the trochlea during inferior oblique action. These clinical features have been reported in association with SLE [3], 
Sjogren's syndrome [4], JRA [5] and RA [6]. In the latter, a stenosing tenosynovitis of the superior oblique tendon sheath causes mechanical obstruction when attempting to raise the eye in adduction. The problem resembles trigger finger in the hands of RA patients [7]. Despite the common association of tenosynovitis with rheumatoid arthritis, Brown syndrome is a rare complication and has been seldom reported. While reviewing the literature, we found only sporadic cases describing Brown's syndrome in association with RA or JRA. Hickling and Beck [8] reported 6 cases during a period of 10 years. Other case reports describe only one or two patient in each case. Interestingly, Brown's syndrome may appear when RA is quiet under DMARDs treatment [9], as well as during disease exacerbation. On the other hand, spontaneous resolution of this condition may occur [10]. The traditional treatment of Brown's syndrome is corticosteroids with complete resolution of the disease in most cases [11]. Our case is also unique since it appeared after pregnancy as the first presenting sign of RA exacerbation and recurred in the same circumstances in the another eye. The mild residual symptoms observed in our patient may suggest a possible congenital malformation of the tendon.

\section{Conclusion}

We have reported a rare case of recurrent Brown syndrome after pregnancy in a patient with JRA. Because of rarity of this syndrome, it is probably often under diagnosed. Increased awareness to the possibility of tenosynovitis of the superior oblique tendon as a manifestation of active RA may prompt its diagnosis and treatment.

\section{REFERENCES}

[1] S. C. Reddy and U. R. Rao, "Ocular Complications of Adult Rheumatoid Arthritis," Rheumatol International, Vol. 16, No. 2, 1996, pp. 49-52. doi:10.1007/BF01816435

[2] H. W. Brown, "True and Simulated Superior Oblique
Tendon Sheath Syndromes," Document Ophthalmological, Vol. 34, No. 1, 1973, pp. 123-136. doi:10.1007/BF00151801

[3] J. L. Alonso-Valdivielso, B. Alvarez Lario, J. A. López, M. J. Sedano Tous and A. B. Gómez, “Acquired Brown's Syndrome in a Patient with Systemic Lupus Erythematosus," Annals of the Rheumatic Diseases, Vol. 52, No. 1, 1993, pp. 63-64. doi:10.1136/ard.52.1.63

[4] A. K. Brahma, E. Hay, D. A. Sturgess and L. H. Morgan, “Acquired Brown's Syndrome and Primary Sjogren's Syndrome,” The British Journals of Ophthalmol, Vol. 79, No. 1, 1995, pp. 89-90. doi:10.1136/bjo.79.1.89

[5] F. M. Wang, C. Wertenbaker, M. M. Behrens and J. C. Jacobs, “Acquired Brown's Syndrome in Children with Juvenile Rheumatoid Arthritis,” Ophthalmology, Vol. 91, No. 1, 1984, pp. 23-26.

[6] C. Cooper, J. R. Kirwan, N. W. McGill and P. A. Dieppe, "Brown's Syndrome: An Unusual Ocular Complication of Rheumatoid Arthritis," Annals of the Rheumatic Diseases, Vol. 49, No. 3, 1990, pp. 188-189. doi:10.1136/ard.49.3.188

[7] J. H. Sandford-Smith, "Intermittent Superior Oblique Tendon Sheath Syndrome," The British of Journals of Ophthalmol, Vol. 53, No. 6, 1969, pp. 412-417. doi:10.1136/bjo.53.6.412

[8] P. Hickling and M. Beck, "Brown's Syndrome: An Unusual Ocular Complication of Rheumatoid Arthritis," Annals of the Rheumatic Diseases, Vol. 50, No. 1, 1991, p. 66. doi:10.1136/ard.50.1.66-b

[9] M. Beck and P. Hickling, "Treatment of Bilateral Superior Oblique Tendon Sheath Syndrome Complicating Rheumatoid Arthritis," The British of Journals of Ophthalmol, Vol. 64, No. 5, 1980, pp. 358-361. doi:10.1136/bjo.64.5.358

[10] G. N. Fuller, T. D. Matthews, R. N. Maini and C. Kennard, “An Unusual Cause for Diplopia: Acquired Brown's Syndrome," Journal of Neuroogyl Neurosurg Psychiatry, Vol. 58, No. 4, 1995, pp. 506-507. doi:10.1136/jnnp.58.4.506

[11] S. Akar, M. Söylev, F. Onen, E. Ada, M. Birlik and N. Akkoc. “Acquired Brown's Syndrome with Juvenile Idiopathic Arthritis: Resolution with Early Steroid Treatment," Clinical and Experimental Rheumatology, Vol. 19, No. 3, 2001, p. 354. 